\section{LESSON 76}

PAPER: $A 5(148 \times 210 \mathrm{~mm})$.

TARGET TIME: 12 minutes.

Use single-line spacing and indented paragraphs to type a correct copy of this article.

Sometimes numbers are written under the words to be transposed to indicate the order in which they are to be typed.

Letter 36

PAPER: A5 (148 $\times 210 \mathrm{~mm})$.

TODAY'S DATE

TARGET TIME: 12 minutes.

Take one carbon copy.

Tabulation 29

PAPER: A5 (210 × $148 \mathrm{~mm})$.

TARGET TIME: 15 minutes.

Rule up in ink or ball point pen.

UNIT 19

\section{HOBBIES}

ac./l.c. I hobby is something which feople take up as a means of relaxing their from normal work. Quite often these hobbies are taken up when people are $\mathrm{m} / \mathrm{f} /$ students and stay with they for liye, though more $r \mid y /$ often than not not they are something which occup I/ \# peoplqs full attention fora short time and then they e/N.P. are forgotton. [A hobby is a great way to relax and s/ very often they result in the expenditure of a lot of a lot of time and money and a study in depth of

b) some quite out-of-the-way sugjects.

$\mathrm{m} /$ It sophetimes happens that a hobby can make a

,/ lot of money for a person as for examplg if a $\mathscr{r} / \mathrm{stet}$ valuable stamp for painting is flovetas a result of a hobby.

Ref $K P$

Mr. Michacl Greenhough, 14 Holdich street, Camberley, Surrey CA79HS or mor Greenhough, 1 am sorry 2 inform $y$ th due to lack of support we ho had to cancel $t$ Advanced level German Course 4 which $y$ applied. [H is a regulation th N.P. there must be a minimum of 10 students in ea. class a this no. has not be reached. [We enclose yo rethd cheque a will infram $y$ N.P. sha $t$ courses run nxt yr. Yours ffly Ken Patainson Head of Deparconeat. Enc.

c. S.E. Pupils

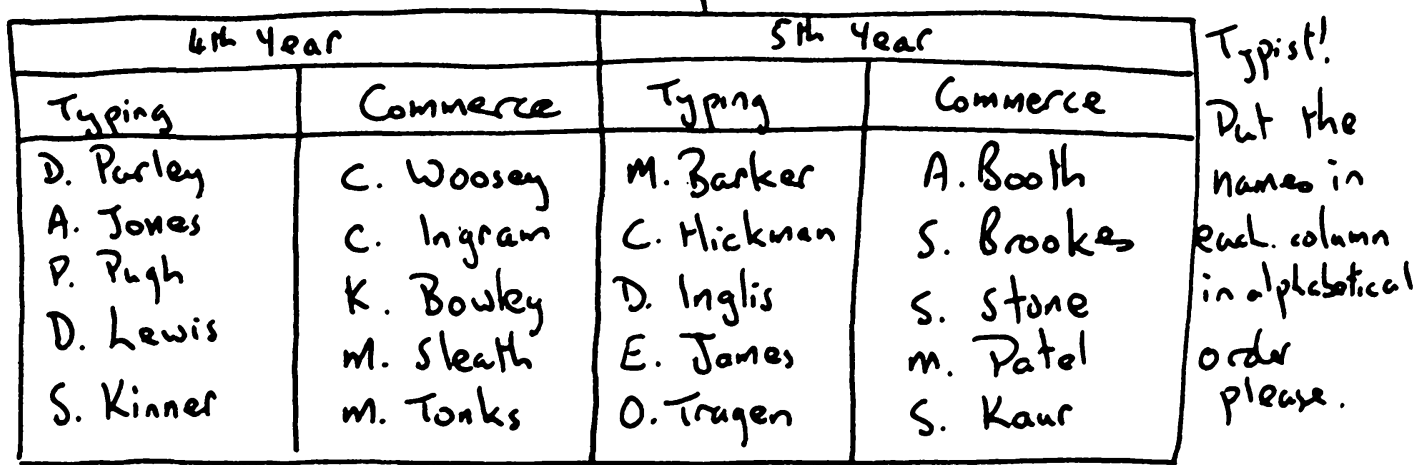

LESSON 76 